\title{
Luminescence, Chiroptical, Magnetic and Ab-initio Crystal- Field Characterizations of an Enantiopure Helicoidal Yb(III) Complex: the van Vleck Rennaissance
}

Frédéric Gendron,, ${ }^{\mathrm{a}, \#}$ Sebastiano Di Pietro,, ${ }^{\mathrm{b}, \#}$ Laura Abad Galan,, François Riobé, ${ }^{\mathrm{b}}$ Virginie Placide, ${ }^{\mathrm{b}}$ Laure Guy, ${ }^{\mathrm{b}}$ Francesco Zinna, ${ }^{\mathrm{c}}$ Lorenzo Di Bari, ${ }^{\mathrm{c}, *}$ Amina BensalahLedoux, ${ }^{d}$ Yannick Guyot, ${ }^{d}$ Guilaume Pilet, ${ }^{e}$ Fabrice Pointillart, ${ }^{a}$ Bruno Baguenard, ${ }^{d}$ Stephan Guy, ${ }^{\mathrm{d}, *}$ Olivier Cador, ${ }^{a}$ Olivier Maury, ${ }^{\mathrm{b}, *}$ Boris Le Guennic ${ }^{\mathrm{a}, *}$

[a] Dr. F. Gendron, Dr. F. Pointillart, Pr. O. Cador, Dr. B. Le Guennic

Univ. Rennes, CNRS, ISCR (Institut des Sciences Chimiques de Rennes) - UMR 6226, F-35000 Rennes (France)

E-mail: boris.leguennic@univ-rennes1.fr

[b] Dr. S. Di Pietro, Dr. L. Abad Gallan, Dr. F. Riobé, Dr. L. Guy, Dr. O. Maury

Univ. Lyon, ENS de Lyon, CNRS Laboratoire de Chimie UMR 5182, Université Claude Bernard Lyon 1, F-69342 Lyon, France.

E-mail: olivier.maury@ens-lyon.fr

[c] Dr. F. Zinna, Pr. L. Di Bari

Dipartimento di Chimica e Chimica Industriale, Università di Pisa, via Moruzzi 13, 56124 Pisa (Italy)

E-mail: Iorenzo.dibari@unipi.it

[d] Dr. B. Baguenard, Dr. A. Bensalah-Ledoux, Pr. S. Guy, Dr. Y. Guyot

Univ. Lyon, Institut Lumière Matière, UMR 5306 CNRS-Université Claude Bernard Lyon 1, 10 rue Ada Byron, 69622 Villeurbanne Cedex,

France. E-mail: Stephan.guy@univ-lyon1.fr

[e] Dr. G. Pilet

Univ. Lyon, Laboratoire des Multimatériaux et Interfaces (LMI), UMR 5615 CNRS-Université Claude Bernard Lyon 1, 43 boulevard du 11 novembre 1918, 69622 Villeurbanne cedex, France.

\# These authors contributed equally to the work. 


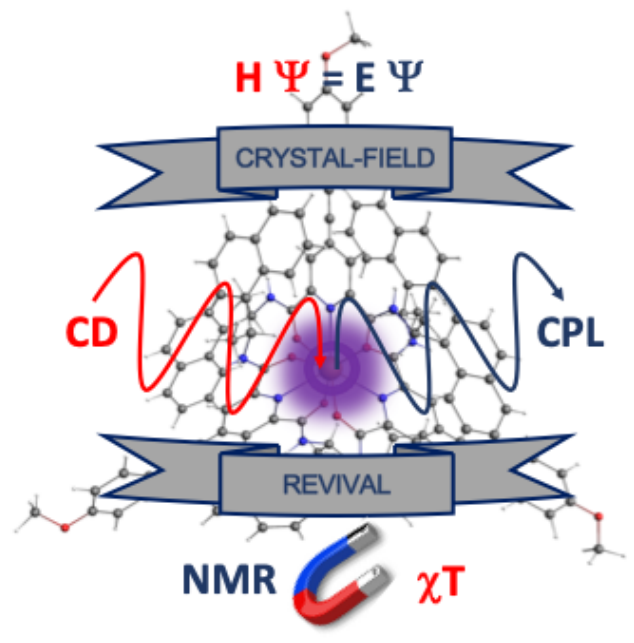

Abstract

The electronic structure of a chiral $\mathrm{Yb}$ (III)-based complex is fully determined by taking advantage of experimental magnetic, luminescence, and chiroptical characterizations in combination with ab-initio wavefunction calculations. The combined use of these techniques allows determining with high resolution the electronic structure diagram as well as the nature of the different states involved in the magnetic and chiroptical properties of the investigated complex. The different crystal-field pictures deduced from spectroscopic measurements are re-conciliated in light of the magnetic properties and ab-initio results in the frame of the van Vleck initial vision. Advanced ab-initio calculations demonstrate that global chiroptical spectra correspond to the sum of intricated transitions with similar or opposite polarizations. 


\section{INTRODUCTION}

The presence of a partially filled $4 \mathrm{f}$ valence shell in lanthanide(III) ions has been the origin of an incredible raise in the Ln-based chemistry over the past decades. Among the large panel of applications, the most striking use of such complexes can be found in the recent development of new molecular magnets, ${ }^{1}$ named single-molecule magnets (SMMs), which aim at elaborating high density data storage devices, or in the development of $\mathrm{Ln}(\mathrm{III})$ luminescent probes for bio-medical purposes. ${ }^{2}$ Additionally, chiral Ln(III)-based complexes have been used lately to achieve circularly polarized luminescence (CPL) ${ }^{3}$ for applications in biological sensing, ${ }^{4}$ anti-counterfeiting devices ${ }^{5}$ and organic lightemitting diodes (CP-OLEDs) for their appealing use in display technology. ${ }^{6}$ In all of these cases, the magnetic, luminescence and chiroptical properties arise from the same origin: the crystal-field (CF) interaction generated by the ligand sphere around the $\mathrm{Ln}(\mathrm{III})$ ion that lifts the degeneracy of the ${ }^{2 \mathrm{~S}+1} \mathrm{~L} J$ ground and excited terms.

Indeed, for an isolated $\operatorname{Ln}(\mathrm{III})$ ion the $4 \mathrm{f}$ transitions are Laporte forbidden, preventing any optical activity due to the vanishing electric transition dipole moments. The presence of a coordination sphere that does not contain an inversion center, allows to (i) break the parity rule and (ii) lift the degeneracy of the ${ }^{2 S+1} \mathrm{~L}$ Jerms, giving rise to optical properties. ${ }^{7}$ Similarly, the CF interaction is mandatory to generate the large magnetic anisotropies required for SMMs. In fact, an isolated $\operatorname{Ln}(\mathrm{III})$ ion only exhibits an isotropic magnetic moment of magnitude $\boldsymbol{g}_{j} \sqrt{\boldsymbol{j}(\boldsymbol{j}+\mathbf{1})} \boldsymbol{\mu}_{\boldsymbol{B}}$ corresponding to the magnetic moments average of the different $\mathrm{M}_{\lrcorner}$states of the ground term. Depending on the symmetry and magnitude of the $\mathrm{CF}$, the $\mathrm{M}$ s states are allowed to mix with each other's and the degeneracy of these states is lifted, inducing potential magnetic anisotropy. Therefore, in order to be able to tune the optical, chiroptical and magnetic properties in $\mathrm{Ln}$ (III)-based complexes, it is necessary to perfectly characterize and rationalize the CF interactions.

Over the last few years, magneto-luminescence correlations have been used in combination with ab-initio multiconfigurational wavefunction calculations to probe in detail the electronic structure of several $\mathrm{Ln}(\mathrm{III})$-based SMMs ${ }^{8}$ involving mainly terbium (III), ${ }^{9}$ dysprosium (III), ${ }^{10}$ and ytterbium(III). ${ }^{11}$ In these examples, the luminescence of the Ln(III) ions was used as a snapshot of the energetic splitting of the ground ${ }^{2 \mathrm{~S}+1} \mathrm{~L} \mathrm{~J}$ terms, allowing (i) a direct comparison with the ab-initio electronic structure calculations and (ii) a rationalization of the magnetic properties. The proof of concept was then extended with the use of low-temperature luminescence measurements, allowing an improvement of the spectra's resolution by removing a sizable number of extra transitions corresponding to "hot bands". ${ }^{12}$ However, the assignment of these hot bands is not straightforward and can be easily over-interpreted by the presence of additional effects such as vibronic ones. ${ }^{11 d}$ Despite its wide use, ab-initio calculations might fail as well to provide accurate electronic structure information, particularly for strongly correlated systems such as ytterbium-based complexes, where electronic correlation and covalent effects are important and remain challenging to tackle with ab-initio methods.

To circumvent such limitations in the high-resolution characterization of the Ln(III) CF interactions, one step further would be to take advantage of the presence of potential chirality. Indeed, the presence of chiral ligands, or of achiral ligands wrapped around the $\mathrm{Ln}(\mathrm{III})$ ion with a $\Lambda$ - or $\Delta$-helicity, generates enantiomers that interact differently with linearly and circularly polarized light. These enantiomers will absorb or emit photons preferentially with one sense of circular polarization. The presence of additional transition selection rules improves the discrimination of each contribution in the absorption and emission spectra, and in combination with the magnetic and luminescence measurements, it should become possible to determine without ambiguities the electronic structure diagram of the investigated Ln(III) complexes, and hence the CF interactions. Such an enhanced analysis would ideally require that the transitions do not overlap. 
However, in the general case, the detected signals consist of a sum of individual transitions with identical or opposite signs, which may lead to erroneous interpretations. For instance, a lack of chiroptical signal at a certain energy may be due to opposite components cancelling each other.

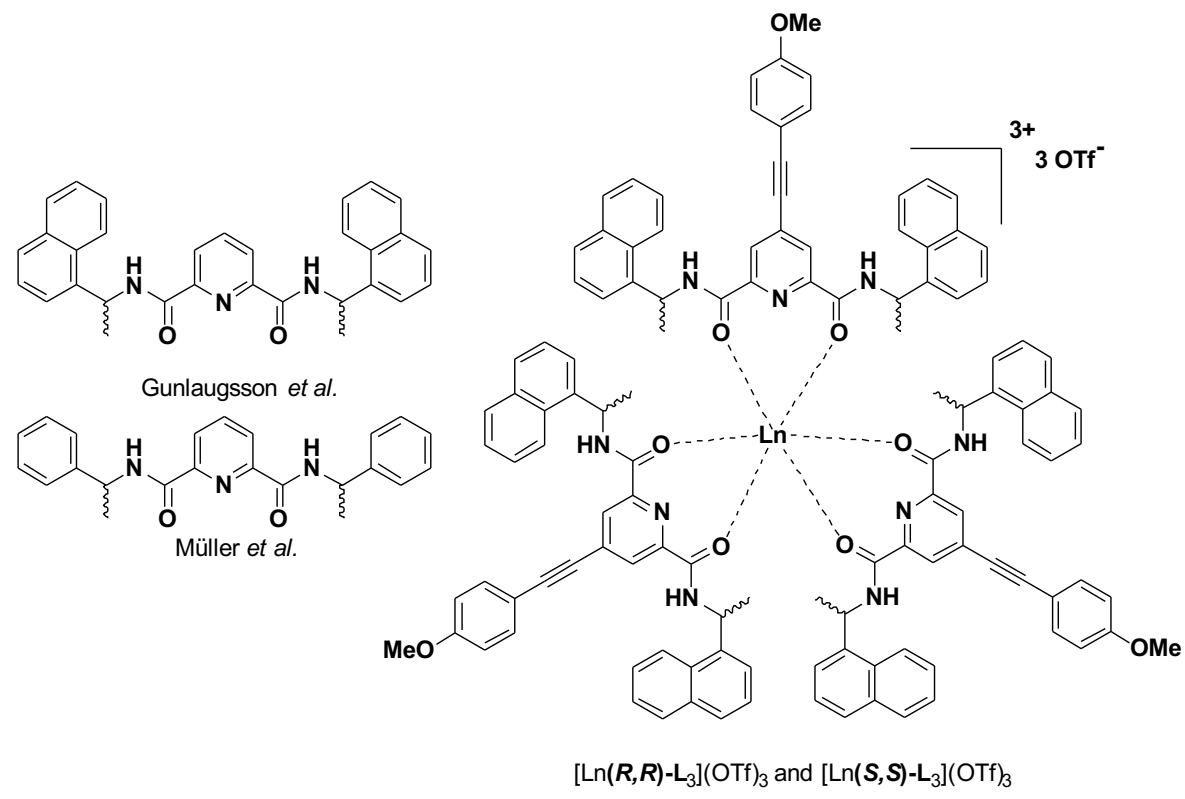

Chart 1. Tridentate ligand leading to the formation of 3-fold symmetric lanthanide complexes featuring an helicoidal chirality. ${ }^{13}$

Herein we present the synthesis, the structural determination, and the spectroscopic characterizations of a helical $\mathrm{Yb}(\mathrm{III})$-based complex containing a charge transfer antenna, functionalized version of an analogous chiral complex developed by Muller and Gunnlaugsson (see Chart 1). ${ }^{13}$ Our objective is to fully characterize the CF of this chiral $\mathrm{Yb}(\mathrm{III})$ complex by combining magnetic measurements in solid state, with room and low-temperature luminescence measurements, room temperature circular dichroism (CD) absorption and with an innovative CPL NIR technique carried out for samples in solution. The electronic structures, and hence the CF parameters derived from these measurements, were confronted to the results of ab-initio calculations. As originally highlighted by van Vleck, ${ }^{14}$ the "reconciliation of the different facts is far from easy, and so [...] the entire subject is referred as a puzzle as far as existing knowledge is concerned".

\section{Ligands and Complexes Synthesis}

The synthesis of the target ligand consists of the reaction of chelidamic acid (4-hydroxypyridine-2,6-dicarboxylic acid dihydrate) with thionyl chloride to form the transient acid chloride that further reacted with 2,6-bis-N-substituted chiral amide $(R)-(+)$ - or (S)-(-)- 1-(1-naphthyl)ethylamine (see Scheme S1). During this step, the simultaneous aromatic nucleophilic substitution in para-position with a chloro atom was achieved. After replacement of the chloro with a iodo atom using already reported procedure ${ }^{15}$ the palladium-catalyzed Sonogashira cross-coupling with 4-ethynyl anisole was performed to yield the two enantiopure antennas $(R, R)$ - and $(S, S)$-L, obtained with an overall yield of ca. $50 \%$ for both the enantiomers (Scheme S1, for the detailed procedure see the experimental section and the ESI). The enantiopure complexes are synthesized in a 1:1 mixture of methanol and dichloromethane by adding the lanthanide salt $\left(\mathrm{LnOTf}_{3}, \mathrm{Ln}=\mathrm{Nd}, \mathrm{Pr}, \mathrm{Eu}, \mathrm{Dy}, \mathrm{Tm}, \mathrm{Er}, \mathrm{Yb}\right.$ and $\left.\mathrm{Lu}\right)$ to 3 equivalents of each enantiomer of the ligands $(\boldsymbol{R}, \boldsymbol{R})-\mathrm{L}$ or 
(S,S)-L (Scheme S1): the complexation process is instantaneous, accompanied by a slight color change of the solution from pale to more intense yellow. The pure complexes are isolated by filtration, after a precipitation adding diethyl ether, and fully characterized by ${ }^{1} \mathrm{H},{ }^{13} \mathrm{C}$ NMR and HRMS (see ESI).

\section{Solid-State and Solution Structures}

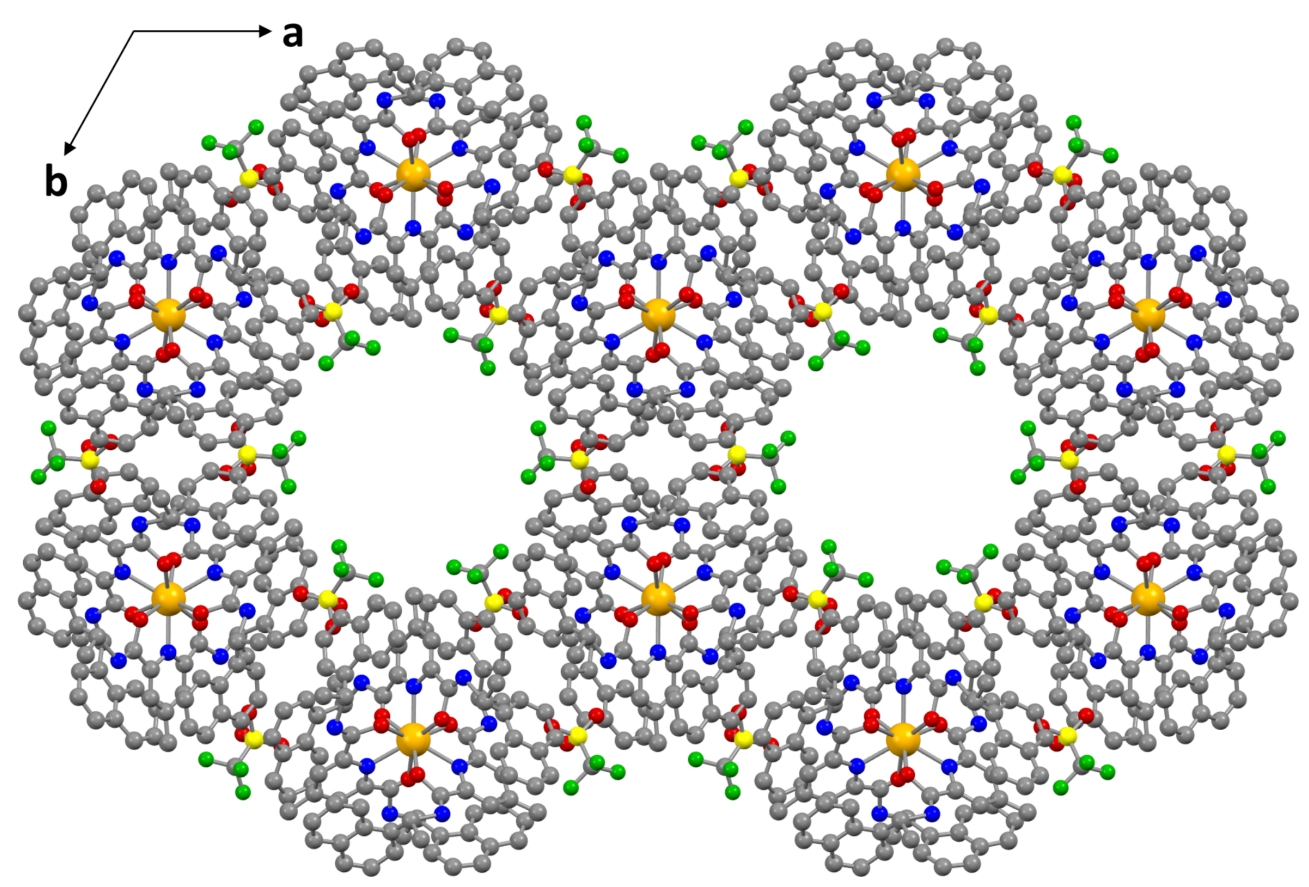

Figure 1. Partial X-ray structure of the $\left[\operatorname{Er}(R, R)-\mathrm{L}_{3}\right](\mathrm{OTf})_{3}$ representing the packing as viewed along the $c$ crystallographic axis. The 4-ethynylanisole moiety have not been determined and were replaced by methyl fragments. Protons have been omitted for clarity. Er, O, N, C, F and S atoms are in orange, red, blue, grey, green and yellow, respectively.

Single crystals for $\mathrm{X}$-ray diffraction were grown as yellow needles by slow diffusion of diethyl ether in a methanol solution of the complexes. The best data were collected with crystals of the $\left[\operatorname{Er}(R, R)-L_{3}\right](\mathrm{OTf})_{3}$ complex. Unfortunately, only a partial structure was determined (see Figure 1), which misses the 4-ethynyl-anisole moiety on each ligand unit. Only the alkyne carbon directly linked to the pyridine ring could be unambiguously located in the electronic density map. However, a comparison can be made with the parent system reported previously by Gunnlaugsson et al. and shown in Figure S1. ${ }^{13 a}$ The three $(\boldsymbol{R}, \boldsymbol{R})$-L ligands wrap around the lanthanide ion with a $\Lambda$-helicity promoting the $\pi$-interactions in-between each pyridine and naphthalene rings from the two other ligands (Figure S2). Surprisingly, in spite of the presence of the additional $\pi$-extended antennas, the complex crystals are almost isostructural to what previously observed within a $\mathrm{P}_{3}$ chiral space group (Figure S1). An identical hexagonal packing of the complex, promoted by intermolecular $\pi-\pi$ stacking in-between naphthalenes, led to the formation of solvent channels where the ethynyl-anisole moieties stretched (Figure 1). Considering the ca. $8 \AA$ radius of these cavities, a high degree of structural disorder of the antennas is expected, induced both by a possible free rotation of the terminal phenyl rings and steric clash of the three methoxy groups at the center of the channel. 


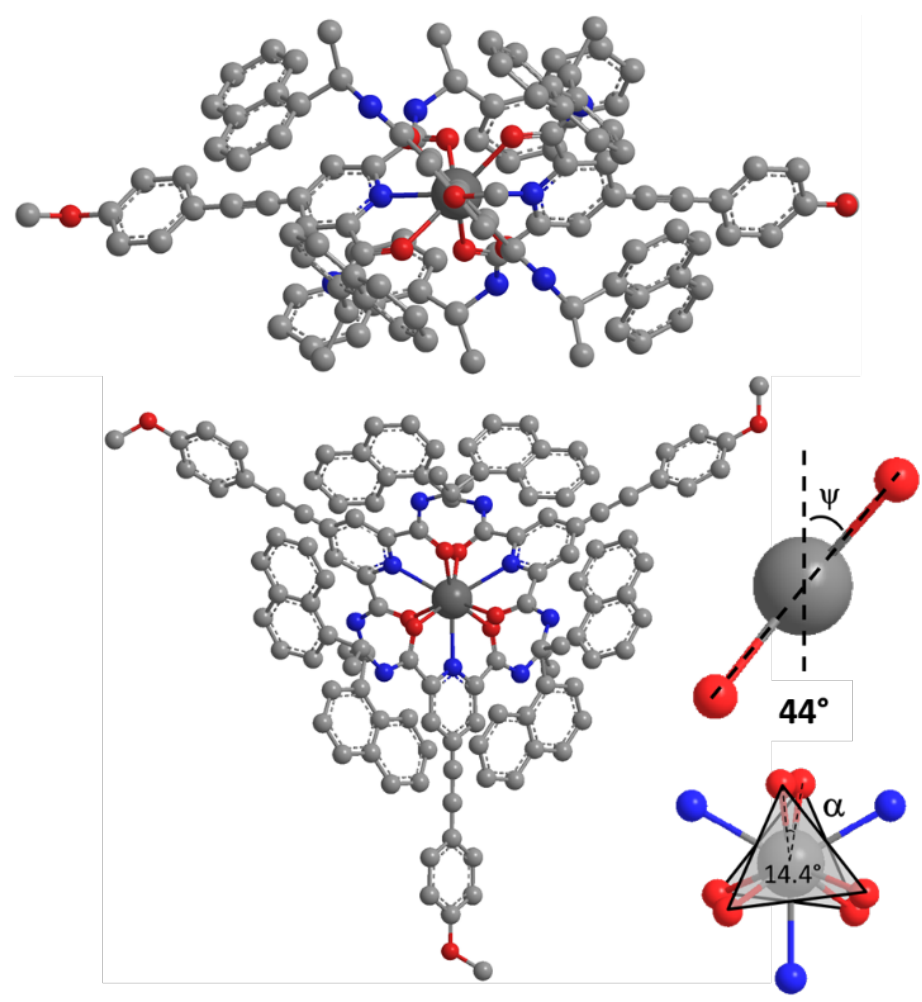

Figure 2. Chem3D model of $\left[\mathrm{Yb}(R, R)-\mathrm{L}_{3}\right]^{3+}$ PERSEUS structure along two views (hydrogen atoms omitted for clarity) with highlighted two important angles characterizing the polyhedron. Color code: $\mathrm{C}$ in gray, $\mathrm{N}$ in blue, $\mathrm{O}$ in red, $\mathrm{Yb}$ in dark gray.

To tackle this drawback, the solution structure of the $\left[\mathrm{Yb}(R, R)-\mathrm{L}_{3}\right](\mathrm{OTf})_{3}$ complex was determined with the PERSEUS (Paramagnetic Enhanced Relaxation and Shift for Eliciting the Ultimate Structure) program ${ }^{16}$ and the resulting structure is given in Figure 2. Such procedure has been successfully applied to determine the solution structures of a large number of Ln-based complexes. ${ }^{17}$ It takes advantage of the high sensitivity of the NMR paramagnetic shifts to the complex geometry. ${ }^{18}$ Indeed, if one assumes that the spin density is localized at the Ln(III) nucleus, the paramagnetic NMR shift of a ligand nuclei $i$ is then dominated by the pseudo-contact term $\left(\delta^{\mathrm{PC}}(i)\right),{ }^{19}$ which is strongly dependent on the relative position of this nuclei with respect to the principal magnetic susceptibility anisotropy axes. Details about the full procedure are given in ESI. As expected, the coordination polyhedron configuration of the solution structure is $\Lambda$ with the $(\boldsymbol{R}, \boldsymbol{R})$-L enantiomer and its shape is better described as a slightly distorted tricapped trigonal prism: the $\alpha$ angle, which quantifies the distortion from the regular prism, has a value of $14^{\circ}$ with the polyhedron close to be achiral (Figure 2). The skewed angle $\psi$ of the pyridine 2,6-bis-amide plane (which involves also the conjugated anisole moiety) with respect to the $D_{3}$ axis is $44^{\circ}$ and confirms the moderate $\delta^{\mathrm{PC}}(i)$ observed. Moreover, the dihedral angles $\mathrm{C} 11-\mathrm{N}-\mathrm{C} 12-$ $\mathrm{C} 13=85^{\circ}$ and $\mathrm{Me}-\mathrm{C} 12-\mathrm{C} 13-\mathrm{C} 21=79^{\circ}$ (see Figure $\mathrm{S} 15$ for the numbering) describe the orientation of the naphtyl rings in space: the rings of one ligand unit are perfectly oriented for a $\pi$-stacking interaction with the pyridine rings of the others (distance around 4-4.5 $\AA$ ). The strength of this interaction is a key point of the stability of the system and it can be interpreted as a case of a multi $\pi$-stacking network between electron rich rings naphtalenes and an electron poor pyridine. Moreover, the ethynyl anisole moiety is perfectly coplanar with the 2,6-bis amido pyridine plane. All these 
structural parameters obtained from the solution structure determination compared well with those obtained by X-ray diffraction (Table S1).

\section{Magnetic Characterizations}

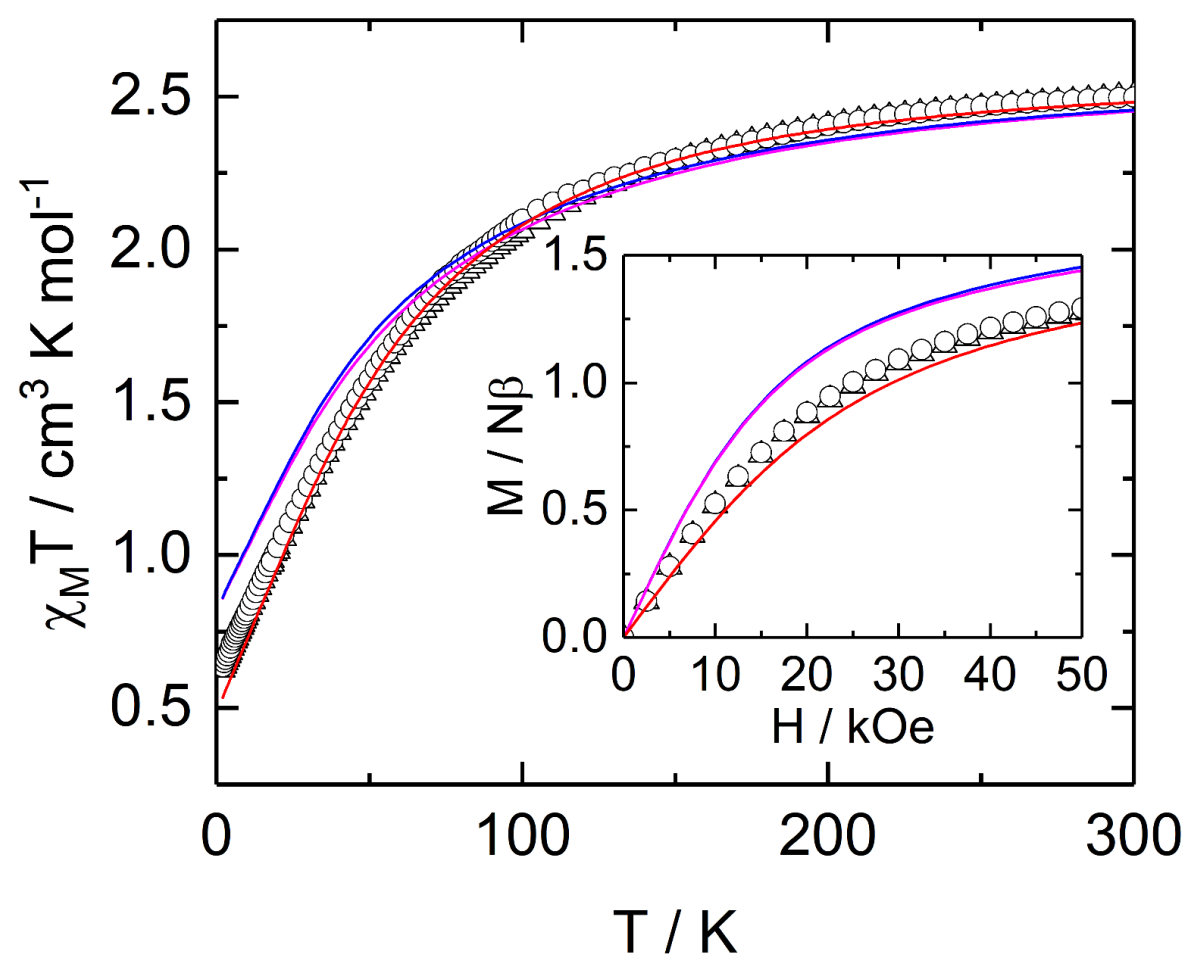

Figure 3. Experimental thermal variations of $\mathrm{XM}_{M} \mathrm{~T}$ (in $\mathrm{cm}^{3} \mathrm{~K} \mathrm{~mol}^{-1}$ ) for the $\left[\mathrm{Yb}(\boldsymbol{R}, \boldsymbol{R})-\mathrm{L}_{3}\right](\mathrm{OTf})_{3}$ (black circles) and $[\mathrm{Yb}(\boldsymbol{S}, \boldsymbol{S})$ $\left.\mathbf{L}_{3}\right](\mathrm{OTf})_{3}$ (black triangles) with simulated curves: ab-initio PT2-SO (red line) and crystal field (see text for details) analyses (solution luminescence: magenta, solid state luminescence: blue). Inset: magnetization curves at $2 \mathrm{~K}$ with identical color code.

Magnetic studies were performed on microcrystalline powders of the $\mathrm{Yb}(\mathrm{III})$ derivatives and as expected, the two enantiomers behave similarly since the two $X_{M} T$ vs. $T$ curves are perfectly superimposed (Figure 3). At room temperature, the $X_{M} T$ values $\left(2.5 \mathrm{~cm}^{3} \mathrm{~K} \mathrm{~mol}^{-1}\right)$ agree with the expected value for ${ }^{2} F_{7 / 2}$ multiplet ground state with g $=$ $8 / 7\left(2.57 \mathrm{~cm}^{3} \mathrm{~K} \mathrm{~mol}^{-1}\right)$. On cooling, $X_{M} T^{\prime}$ 's decrease down to $0.63 \mathrm{~cm}^{3} \mathrm{~K} \mathrm{~mol}^{-1}$ due to the splitting of the multiplet ground state. The $\mathrm{M}$ vs $\mathrm{H}$ curves are also perfectly superimposed as expected (inset of Figure 3 ). These two systems do not show any out-of-phase component of the ac susceptibility in zero external dc field. They are not zero field SMM down to $2 \mathrm{~K}$. The example of $\left[\mathrm{Yb}(S, S)-\mathrm{L}_{3}\right](\mathrm{OTf})_{3}$ is given on Figure $\mathrm{S} 3$ and only the data for this compound will be presented here below. The application of a moderate external dc field induces an out-of-phase signal in the frequency window (1$1500 \mathrm{~Hz}$ ) that does not significantly shift with the applied field but grows in amplitude (Figure S3). One can estimate that the optimum field for which the signal appears at the lowest frequency with the maximum amplitude is close to 1 kOe (Figure S3). At this field, the variation of the ac susceptibility with the oscillation frequency of the magnetic field can be quantitatively analyzed in the framework of the extended Debye model (see Figure 4 and Figure S4). The nonrelaxing fraction of the magnetic susceptibility remains relatively small $(\sim 17-20 \%)$ that means that the vast majority of the magnetic moments are involved in the relaxation process (Table S2). The distribution of the relaxation time remains 
small with a below 0.1 whatever the temperature (Table S2). a close to 1 means an infinite distribution of the relaxation time while a close to 0 means a single relaxation time. The thermal variation of the relaxation time (Figure 5) is reproduced with only Raman and direct relaxation processes $\left(\tau^{-1}=C T^{n}+A H^{4} T\right){ }^{20}$ The best-fitted curve is obtained with $\mathrm{C}=75.22 \mathrm{~s}^{-1} \mathrm{~K}^{-\mathrm{n}}, \mathrm{n}=5.37, \mathrm{~A}=2.21 \times 10^{-9} \mathrm{~s}^{-1} \mathrm{Oe}^{-4} \mathrm{~K}^{-1}$ (Figure 5). The Orbach process $\left(\tau^{-1}=\tau_{0}^{-1} \exp (\Delta / T)\right)$ that guides the relaxation pathway through Kramers doublets excited states via Arrhenius law, appears to be too slow with reasonable $\tau_{0}$ values and $\Delta=124 \mathrm{~K}$ (ab initio calculations) to interfere with the relaxation process.

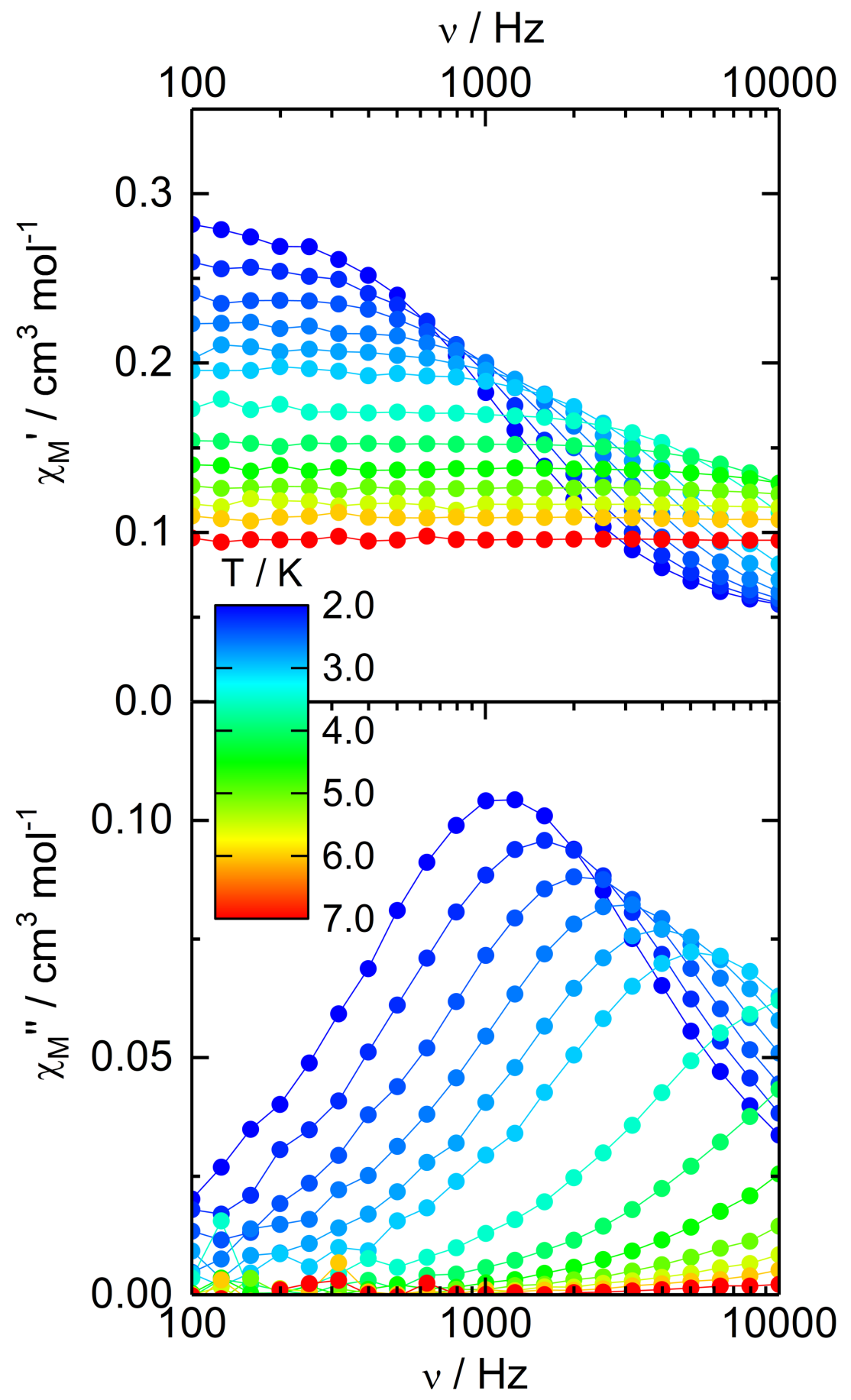


Figure 4. Frequency dependences of the two components, in-phase ( $X_{M}^{\prime}$ : top) and out-of-phase ( $X_{M}{ }^{\prime \prime}$ bottom), of the ac magnetic susceptibility measured at $1 \mathrm{kOe}$ as a function of the temperature for $\left[\mathrm{Yb}(\boldsymbol{S}, \boldsymbol{S})-\mathrm{L}_{3}\right](\mathrm{OTf})_{3}$.

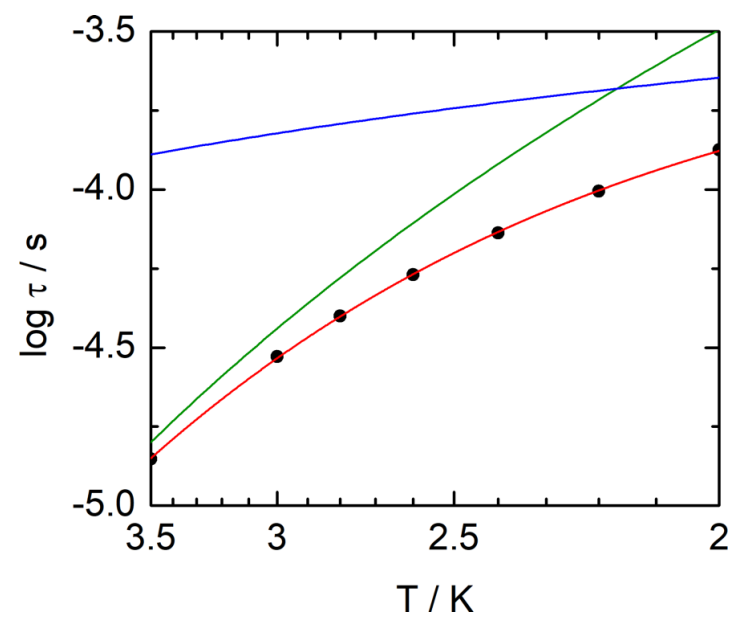

Figure 5. Thermal variation of the relaxation time (black dots) with the best fitted curve in red line and the separated contributions of the Raman (green line) and direct (blue line) processes for $\left[\mathrm{Yb}(S, S)-\mathrm{L}_{3}\right](\mathrm{OTf})_{3}$.

\section{Luminescence Characterizations}

Emission. The luminescence has been studied in solution and in the solid state both at room temperature and at $77 \mathrm{~K}$ (Figure 6). Upon excitation at $360 \mathrm{~nm}$ (Figures S5-S6), the classical $\mathrm{Yb}$ (III) emission profile is observed and corresponds to the ${ }^{2} \mathrm{~F}_{5 / 2} \rightarrow{ }^{2} \mathrm{~F}_{7 / 2}$ transition in the NIR. The emission spectra are similar for both enantiomers (Figure S7). Decreasing the temperature down to $77 \mathrm{~K}$ considerably narrowed the emission bands, suppressed the "hot bands" contribution and revealed the crystal field splitting fine structure. In a threefold symmetry, the ${ }^{2} \mathrm{~F}_{7 / 2}$ multiplet ground state splits in four CF states noted $0,1,2,3$ and in three for the ${ }^{2} \mathrm{~F}_{5 / 2}$ excited state noted $0^{\prime}, 1^{\prime}, 2^{\prime}$. Erreur ! Argument de commutateur inconnu. In the $77 \mathrm{~K}$ solid state spectrum, four signals - three main peaks and one shoulder - can be clearly identified using Gaussian deconvolution (Figure S8, 979.2, 989.8, 998.2, $1013.7 \mathrm{~nm}$ ) and consequently the energy diagram can be deduced assigning the $979.2 \mathrm{~nm}\left(10213 \mathrm{~cm}^{-1}\right)$ as the zero-line transition (ZLT) $(0,109,194$, $348 \mathrm{~cm}^{-1}$ ). This simple spectroscopic experimental measurement enables a direct reading of the ${ }^{2} \mathrm{~F}_{7 / 2}$ ground state $\mathrm{CF}$. In frozen solution, the similar structure induces a comparable energy diagram obtained from the luminescence spectrum (Figures 6 and S8, 0, 107, 201, $355 \mathrm{~cm}^{-1}$ ). Note that the experimental error for such measurements is in the nanometer range and corresponds to a precision in the energy splitting determination estimated to $+/-10 \mathrm{~cm}^{-1}$. The two CF splitting obtained in frozen solution and in the solid state at $77 \mathrm{~K}$ are almost identical, indicating that the coordination sphere remains the same in both cases. It is well known that the total CF splitting is a signature of the local symmetry of the $\mathrm{Yb}$ (III) coordination polyhedron. ${ }^{21}$ In the present case, the total splitting noted $\Delta_{\mathrm{CF}}$ is small, about $348 \mathrm{~cm}^{-1}$ in the solid state (355 $\mathrm{cm}^{-1}$ in frozen solution). This value is perfectly in line with that previously determined in the literature for three-fold complexes like tris-dipicolinate $\left(\Delta_{\mathrm{CF}}=348 \mathrm{~cm}^{-1}\right),{ }^{22}$ helicates $\left(\Delta_{\mathrm{CF}}=372 \mathrm{~cm}^{-1}\right),{ }^{23}$ or murex complexes $\left(\Delta_{\mathrm{CF}}=\right.$ $\left.366 \mathrm{~cm}^{-1}\right)$ Erreur ! Argument de commutateur inconnu. ${ }^{\mathrm{b}}$ and much lower than that of $C_{2 v}\left(\Delta_{\mathrm{CF}}=670 \mathrm{~cm}^{-1}\right)^{24}$ or even lower symmetry complexes $\left(\Delta_{\mathrm{CF}}\right.$ up to $\left.880 \mathrm{~cm}^{-1}\right) \cdot{ }^{25}$ Finally, the luminescence lifetime for the two enantiomers of the $\mathrm{Yb}(\mathrm{III})$ complex has been measured (Figure S9) and fitted with a perfect mono-exponential decay giving $\tau=6.1-6.2 \mu \mathrm{s}$, in the classical range for non-deuterated $\mathrm{Yb}(\mathrm{III})$ complexes in organic solution. 

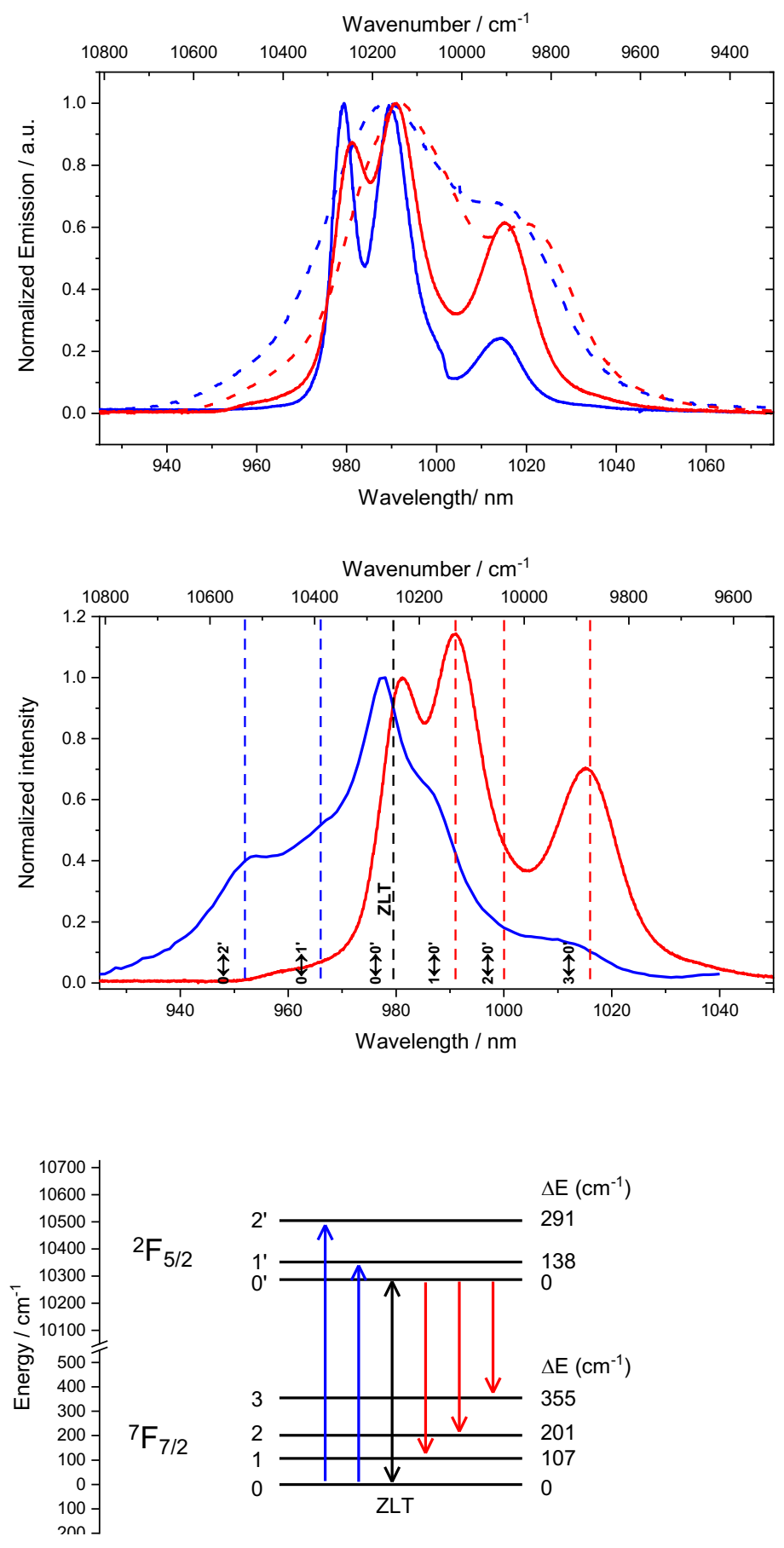

Figure 6. (top) Luminescence spectra of $\left[\mathrm{Yb}(S, S)-\mathrm{L}_{3}\right](\mathrm{OTf})_{3}$ in solution of ethanol : methanol $=4: 1$ at 298 (red dashed) and at $77 \mathrm{~K}$ (red solid); in solid state at 298 (blue dashed) and $77 \mathrm{~K}$ (blue solid). (Middle) Normalized absorption (blue) and emission (red) spectra at $298 \mathrm{~K}$ in methanol. (Bottom) Experimental energy diagram with related transitions.

Absorption. The NIR-absorption spectrum can be measured only in solution and at room temperature. It spreads between 950 and $1050 \mathrm{~nm}$ and presents a rather poor resolution. Overlay with the emission spectrum (Figure 6) confirms the ZLT position at $979.2 \mathrm{~nm}$ in the absorption, as well. At room temperature, the maximum in absorption is 
blue-shifted by $3 \mathrm{~nm}$ compared to the ZLT. Five main structures can be observed. The short-wave part of the spectrum corresponds to the $0 \rightarrow i^{\prime}\left(i^{\prime}=1\right.$ ', 2') transitions (shoulders at 952 and $966 \mathrm{~nm}$ ) while the long wavelength side can be assigned to the transitions from thermally occupied ground state levels (i.e. hot bands in absorption). These three hot absorption bands (991, 1000 and $1016 \mathrm{~nm}$ ) match well the emission spectrum. From this assignment, the CF splitting of the ${ }^{2} \mathrm{~F}_{5 / 2}$ excited state can be deduced as $0,138,291 \mathrm{~cm}^{-1}$.

Boltzmann distribution. The ${ }^{2} \mathrm{~F}_{5 / 2}$ and ${ }^{2} \mathrm{~F}_{7 / 2}$ CF splitting determined above reveals that the multiplet extension ( 300 $\left.\mathrm{cm}^{-1}\right)$ is in the same order of magnitude as kT at room temperature $\left(208 \mathrm{~cm}^{-1}\right.$ at $\left.300 \mathrm{~K}\right)$. This population distribution leads to an overall broadening of the achiral optical features. We have then computed the variation of the Boltzmann's distribution with the temperature using a three and four levels Boltzmann model (see SI for complete calculation, Figure S10). It must be mentioned that all CF states are Kramers doublets and are then all doubly degenerated. A relative distribution of 57,29 and $14 \%$ for the 0 , 1', 2' CF states, respectively, is clearly determined for the ${ }^{2} F_{5 / 2}$ excited state at room temperature. Population of the ground state multiplet is distributed as $46,28,18$ and $8 \%$ for the $0,1,2,3 \mathrm{CF}$ states. These values clearly show that all the multiplets are populated and, consequently, all the $\mathrm{i} \leftrightarrow \mathrm{j}$ transitions can have an impact on the spectra.

\section{Chiroptical Characterizations}

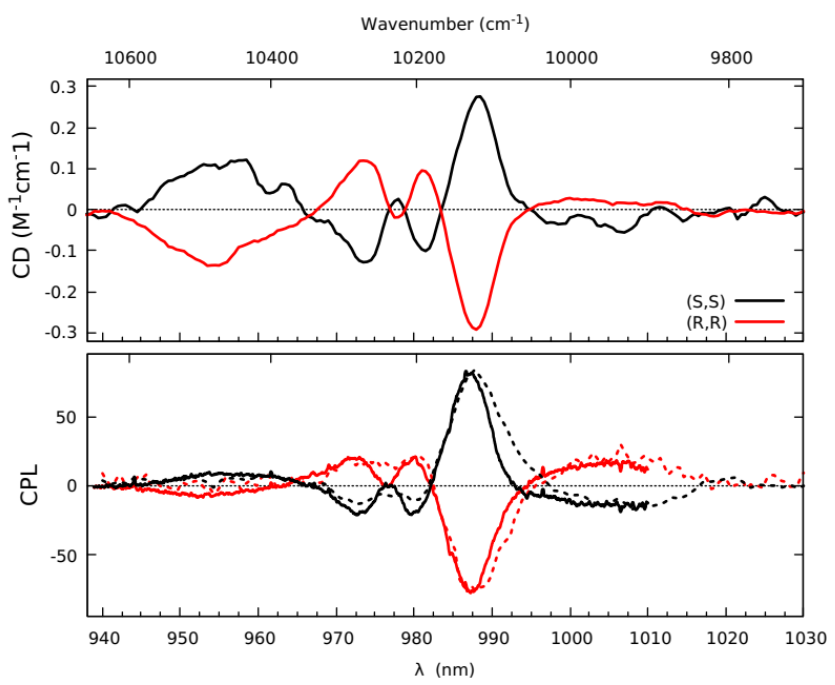

Figure 7. NIR-ECD (top) and NIR-CPL (bottom) spectra of $\left[\mathrm{Yb}(\boldsymbol{R}, \boldsymbol{R})-\mathrm{L}_{3}\right](\mathrm{OTf})_{3}$ (red) and $\left[\mathrm{Yb}(\boldsymbol{S}, \boldsymbol{S})-\mathrm{L}_{3}\right](\mathrm{OTf})_{3}(\mathrm{black})$ complexes in methanol solution at $298 \mathrm{~K}$. For the NIR-CPL, two set-ups were used either with a CCD Si camera (continuous line) or an IR photomultiplier (dotted lines) as detectors.

The chiroptical super-spectrum ${ }^{26}$ of the $\left[\mathrm{YbL}_{3}\right](\mathrm{OTf})_{3}$ complex, combining various chiroptical spectroscopies in different spectral range, visible electronic circular dichroism (ECD), NIR-ECD, circularly polarized luminescence (NIR-CPL) and vibrational dichroism (VCD) was determined for the first time for an ytterbium derivative (Figure 7 and Figures S11S12). The NIR-ECD and NIR-CPL spectra of the two enantiomers of $\left[\mathrm{YbL}_{3}\right](\mathrm{OTf})_{3}$ were recorded in concentrated methanol solution ( $4 \mathrm{mM}$ ) with our home-made apparatus (see Supporting Information). For the CPL, we have used two set-ups: one is based on a CCD camera and waveplates similar to what is used for chiral contrast imaging. ${ }^{27}$ It allows recording one-shot high-resolution spectra but is limited by the sensitivity of the Si sensors. ${ }^{28}$ The other one that uses a standard photoelastic modulator and a single channel detector, is less resolved but can be used down to 1500 
$\mathrm{nm} \cdot{ }^{29} \mathrm{It}$ is worth noting that NIR-chiroptical measurements are relatively rare ${ }^{30}$ compared to visible ones that are widely exemplified for europium(III), terbium(III) and samarium(III) chiral complexes.Erreur! Argument de commutateur inconnu. ${ }^{31}$

NIR-ECD and CPL spectra for the ${ }^{2} \mathrm{~F}_{7 / 2} \leftrightarrow{ }^{2} \mathrm{~F}_{5 / 2}$ transition of the $\left[\mathrm{YbL}_{3}\right](\mathrm{OTf})_{3}$ complexes are displayed in Figure 7 . Erreur ! Signet non défini. This transition is magnetically allowed, highly sensitive to the $\mathrm{Yb}(\mathrm{III})$ ion environment and therefore particularly suited for chiroptical spectroscopy. At room temperature, the ECD and CPL spectra are much more structured than the absorption and emission ones. They are comparable in terms of energetic position and are mirror images for the two enantiomers. The strongest band appears in both ECD and CPL at around $987 \mathrm{~nm}$ (FWHM $=5 \mathrm{~nm}$ ). This band is positive for the $(S, S)$ enantiomer with significant absorption and emission dissymmetry factors $\mathrm{g}$ $=+0.04$ and glum $=+0.11$. On the low energy side of this band, a broad CPL signal of opposite sign extends from 994 to $1016 \mathrm{~nm}$. The corresponding ECD signal is hardly observable as expected for a hot band in absorption. At shorter wavelengths, we clearly count three bands in CPL at 980 (negative), 973 (negative) and $954 \mathrm{~nm}$ (positive) about 4 times lower in intensity. This last transition is much broader (FWHM $=20 \mathrm{~nm}$ ) than the other two (around $5 \mathrm{~nm}$ ). The ECD spectra get the same overall shape but the short wavelength intensities are stronger and a small peak of opposite sign appears between the two peaks at 973 and $980 \mathrm{~nm}$. The different transitions observed at room temperature do not match with the CF splitting determined above. In order to explain this result, ab-initio calculations have been performed (vide infra) and correctly reproduce these spectral features (Figure 9). The short wavelength band (around $950 \mathrm{~nm}$ ) is calculated as a $2^{\prime} \leftrightarrow 0$ transition which also explains the fact that it is more intense in ECD than CPL. This negative band is followed at higher wavelengths by a complicated structure mixing three positive bands involving 0', 1' and 2' states as well as the negative contribution from the $1^{\prime} \leftrightarrow 1$ transition. The exact position, as well as the relative intensities of these bands can lead to the experimental shape observed in the 965-980 nm spectral range (Figure 9). The strong band at $988 \mathrm{~nm}$ is the sum of the $1^{\prime} \leftrightarrow 2,2$ ' $\leftrightarrow 3$ and $0^{\prime} \leftrightarrow 1$ transitions. Its intensity will depend strongly on the temperature of measurements as a consequence of the population repartition in the different ${ }^{2} \mathrm{~F}_{5 / 2}$ sublevels. The long wavelength CPL signal is related to the $1^{\prime} \leftrightarrow 3$ transition, it is thus a hot band in absorption leading to a low ECD signal. Based on all these interpretations, it clearly appears that the apparently well-resolved EDC and CPL spectra at room temperature are in fact the combination of all CF levels and consequently the experimental determination of the energy diagram from room temperature chiroptical data remains hardly possible.

\section{Ab-initio Calculations}

In order to gain further insight into the optical and magnetic properties of the $\left[\mathrm{Yb}(R, R)-\mathrm{L}_{3}\right](\mathrm{OTf})_{3}$ complex, multireference calculations were performed at the SCF/PT2-SO level on a model compound [ $\left.\mathrm{YbL}^{\prime}\right]^{3+}$ resulting from the solution structure determined by NMR (see computational details). The nature of the ground state (GS) was first characterized with the help of the natural spin orbitals (NSOs) as shown in Figure 8. These NSOs represent the distribution of the unpaired electron among the $4 \mathrm{f}$ spin-orbitals. ${ }^{32}$ The largest positive spin-populations (i.e. spin-up) are calculated for the NSOs $4 f_{x y z}\left(0.40 e^{-}\right)$and $4 f_{z}\left(x^{2}-y^{2}\right)\left(0.31 e^{-}\right)$which are associated to a projected orbital angular momentum $m_{1}= \pm 2$. Additionally, a sizable negative spin-population $\left(-0.22 e^{-}\right)$is calculated for the NSO $4 f_{x\left(x^{2}-3 y^{2}\right)}{ }^{2}$ corresponding to $a m_{1}= \pm 3$. The sum of these spin-populations gives a spin expectation value $\left\langle S_{\|}\right\rangle=0.21$, revealing the importance of the SO coupling in the nature of the GS. Using the total angular momentum $\mathrm{J}$ and its projections $\mathrm{M}_{\mathrm{J}}$, the distribution of the unpaired electron derives formally from the Kramers doublet $\mid 7 / 2, \pm 5 / 2>$ of the ${ }^{2} \mathrm{~F}_{7 / 2}$ multiplet. For reference, the composition of this $M_{\lrcorner}$state for a $4 f^{13}$ free ion in term of $m_{l}$ and $m_{s}$ would be of ca. $86 \% \mid \pm 2, \pm 1 / 2>$ and 
$14 \% \mid \pm 3, \pm 1 / 2>$. However, the almost trigonal environment around the $\mathrm{Yb}(\mathrm{III})$ ion in $\left[\mathrm{YbL}_{3}\right]^{3+}$ leads to a mixing of the $M_{J}= \pm 5 / 2$ with the $M_{J}= \pm 1 / 2$ and $\pm 7 / 2$. As seen in Figure 8, the small deviation from a perfectly trigonal environment creates a symmetry breaking in the wave function that is visible with the sizable mixing with the $M_{J}=-3 / 2$ state. This mixing of the different $M_{J}$ states into the SO wave function is responsible for the small magnetic anisotropy of the GS, characterized by the two large perpendicular components of the $g$-factors and a relatively small parallel component $\left(g_{\|}\right.$ $=3.38$ ). The calculated isotropic magnetization is found in really good agreement with the experimental one at very low $T$, suggesting a proper description of the nature of the GS (Figure 3). Additionally, for the temperature-dependence of $\chi_{\mathrm{M}} T$ a nice agreement with the experiment is obtained at the PT2-SO level. This behavior corresponds to the thermal population of the excited $\mathrm{M}_{J}$ states of ${ }^{2} \mathrm{~F}_{7 / 2}$ that are calculated at 86,138 and $290 \mathrm{~cm}^{-1}$ above the GS, respectively.

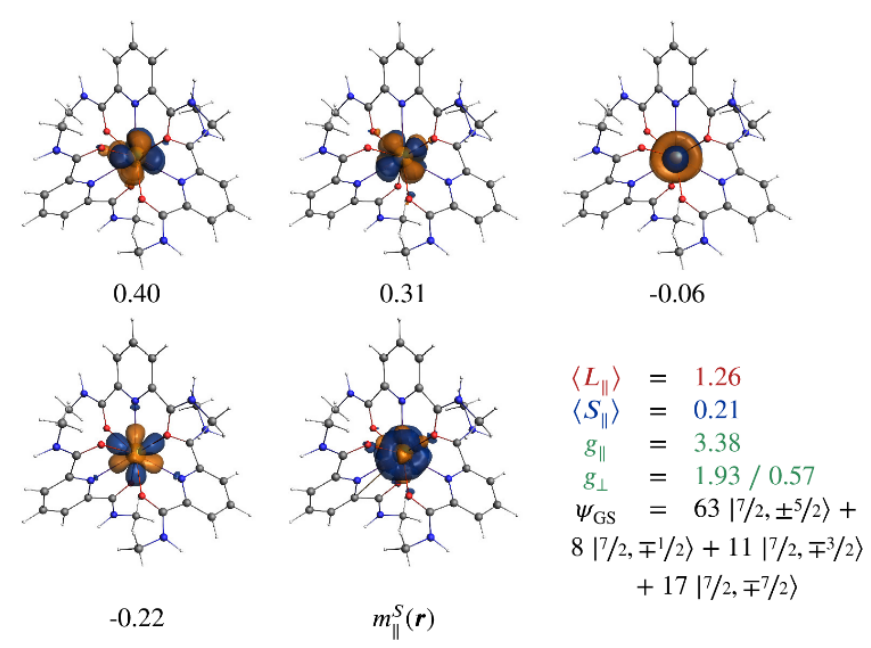

Figure 8. Selected Natural Spin Orbitals (NSOs) (isosurface values $= \pm 0.03$ a.u.) and their corresponding spin populations for the Kramers doublet GS obtained at the PT2-SO level. The isosurface $( \pm 0.001$ a.u.) of the spinmagnetization $\left(m_{\|} S(r)\right)$ for the doublet component $\left\langle S_{\|}>>0\right.$ is also shown. The orbital and spin expectation values, the EPR g-factors and the nature of the wave function calculated for the GS are given for comparison. Additional data are presented in Tables S3 and S4 of the Supporting Information.

The calculated CPL spectrum is shown in Figure 9. Here, the calculations were performed at the RASPT2 level in order to mix the $4 f^{13}$ configurations with the $4 f^{12} 5 d^{1}$ ones. Such a procedure was successfully applied recently to obtained the CPL spectrum of an analogous Eu(III) tris-dipicolinate complex. ${ }^{33}$ At $0 \mathrm{~K}$, the calculated $\mathrm{CPL}$ spectrum exhibits a strong positive and a strong negative band corresponding to the 0 ' $\rightarrow 0$ and 0 ' $\rightarrow 1$ transitions, respectively. The increase of the temperature leads to the appearance of a second positive band corresponding to the 1 ' $\rightarrow 0$ transition, as observed experimentally. However, the comparison with the experimental spectrum suggests that the excited state 1 ' is calculated too low in energy as the intensity of this hot band becomes too important at room temperature. Interestingly, the breakdown of the calculated $\mathrm{CPL}$ spectrum into the different contributions from the three excited states of ${ }^{2} \mathrm{~F}_{5 / 2}$ (Figure 9) reveals that the principal negative CPL band does not only correspond to the 0 ' $\rightarrow 1$ transition as suggested experimentally, but also contains contributions from the 1 ' $\rightarrow 2$ and 2 ' $\rightarrow 3$ transitions. 

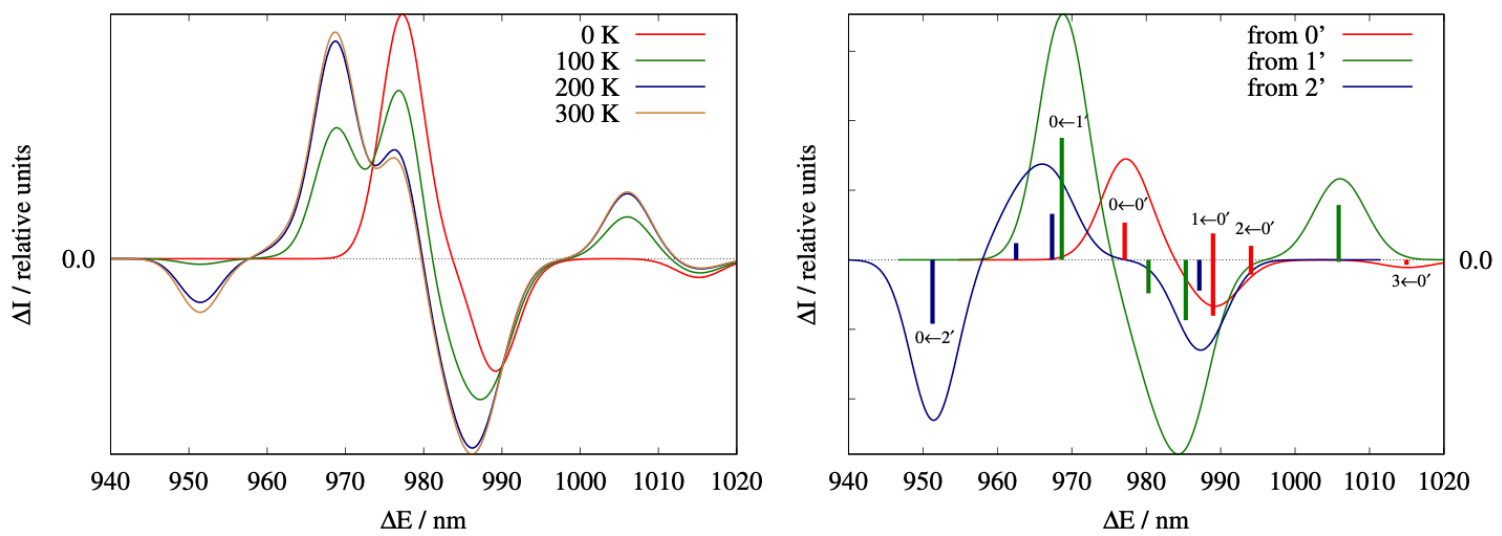

Figure 9. Calculated CPL spectrum of $\left[\mathrm{Yb}(R, R)-\mathrm{L}_{3}\right]^{3+}$ as a function of the temperature (left) and the different contribution at $300 \mathrm{~K}$ from the ${ }^{2} \mathrm{~F}_{5 / 2}$ term. Calculated spectra have been shifted by $0.07 \mathrm{eV}$ to match the experimental 0 ' $\rightarrow 0$ transition. Calculated raw data are given in Table S5.

\section{Crystal-field analysis}

Based on the luminescence characterizations of the $\left[\mathrm{YbL}_{3}\right](\mathrm{OTf})_{3}$ complex, it is then possible to establish its electronic structure and hence, determine the CF parameters. At first, one can assume that the $\mathrm{Yb}$ (III) ion is located in a trigonal environment ( $D_{3}$ symmetry), and express the CF Hamiltonian as:

$$
\widehat{H}^{C F}=\boldsymbol{\alpha}_{\mathrm{J}}\left[\mathbf{B}_{2}^{0} \widetilde{\mathbf{O}}_{2}^{0}(J)\right]+\boldsymbol{\beta}_{\mathrm{J}}\left[\mathbf{B}_{4}^{0} \widetilde{\mathbf{O}}_{4}^{0}(J)+\mathbf{B}_{4}^{3} \widetilde{\mathbf{O}}_{4}^{3}\right]+\boldsymbol{\gamma}_{\mathrm{J}}\left[\mathbf{B}_{6}^{0} \widetilde{\mathbf{O}}_{6}^{0}(J)+\mathbf{B}_{6}^{3} \widetilde{\mathbf{O}}_{6}^{3}(J)+\mathbf{B}_{6}^{6} \widetilde{\mathbf{O}}_{6}^{6}(J)\right] \quad(E q 1 .)
$$

where the $\alpha_{J}, \beta_{J}$ and $\gamma_{\lrcorner}$are parameters obtained using the Wigner-Eckart theorem and depend on the considered Jmanifold (here $J=7 / 2$ ), the $\widetilde{\mathbf{O}}_{\mathbf{k}}^{q}\left(J\right.$ ) are the Stevens operators, and the $\mathbf{B}_{\mathbf{k}}^{\mathrm{q}}$ terms are the CF parameters. Since the ground term ${ }^{2} \mathrm{~F}_{7 / 2}$ is well separated from the excited one (over $10,000 \mathrm{~cm}^{-1}$ ), the matrix elements $\left\langle\mathbf{J}, \mathbf{M}_{\mathbf{J}}\left|\widetilde{\mathbf{O}}_{\mathbf{k}}^{\mathrm{q}}\right| \mathbf{J}, \mathbf{M}_{\mathbf{J}}^{\prime}\right\rangle$ can be simply determined by using the values originally tabulated by Stevens. ${ }^{20}$ In this work, the $\mathbf{B}_{2}^{0}$ term in Eq. 1 was determined by performing luminescence measurement on the $\mathrm{Eu}(\mathrm{III})$ analogue complex and by measuring the energetic splitting of the ${ }^{7} \mathrm{~F}_{1}$ multiplet (see Figure S13). ${ }^{34}$ Indeed, in a trigonal CF the splitting corresponds to 3 times the term $\mathbf{B}_{2}^{\mathbf{0}}$; the sign being determined by the ordering of the degenerate vs non-degenerate components of the multiplet. The analysis of the emission spectrum in solution leads to $\mathrm{J}=1$ transition CF splitting of $90 \mathrm{~cm}^{-1}$, and hence to a $\mathbf{B}_{2}^{\mathbf{0}}$ term equal to ca. $-30 \mathrm{~cm}^{-1}$. The value of $\mathbf{B}_{2}^{0}$ for the $\mathrm{Yb}(\mathrm{III})$ analogue differs probably from the $\mathrm{Eu}(\mathrm{III})$ case. However, theoretical investigations have shown that for a given series and assuming small geometrical relaxations, ${ }^{35}$ the $\mathbf{B}_{2}^{\mathbf{0}}$ remains almost constant along the series, and therefore $\mathbf{B}_{2}^{0}$ was kept fixed at $-30 \mathrm{~cm}^{-1}$. The rest of the $\mathbf{B}_{\mathbf{k}}^{\mathbf{q}}$ terms were then obtained with least-squares procedures by fitting the energies obtained from luminescence measurements carried out on the investigated complex. The results of each sets of CF parameters are given in Table 1 along with the nature of the associated GS. To assess the quality of the fits, the CF parameters were then used to simulate the magnetic properties $\left(\chi_{\mathrm{M}} \mathrm{T}\right.$ product and magnetization) and compared to the experimental data (see Figure 3 ).

As visible in Table 1, the magnitude of CF parameters remains relatively close between the different luminescence measurements. The fact that the $\mathbf{B}_{\mathbf{2}}^{\mathbf{0}}, \mathbf{B}_{\mathbf{4}}^{\mathbf{0}}$ and $\mathbf{B}_{\mathbf{6}}^{\mathbf{0}}$ terms are of the same order of magnitude and all negative leads to a GS that is mainly of $M_{J}= \pm 5 / 2$ character. These small differences in the CF parameters hardly affect $\chi_{M} T$ (see Figure 
3 ), which converges to the experimental data at room temperature. However, at low-temperature the experimental $\chi_{M} T$ is overestimated by the CF analyses, suggesting a too large magnetic moment for the GS. This result is confirmed with the comparison of the fitted magnetization (see Figure 3). The difference at low temperature between the CF analyses and the experimental data can be rationalized with the help of the ab-initio calculations. As mentioned previously, the $\left[\mathrm{Yb}(R, R)-\mathrm{L}_{3}\right](\mathrm{OTf})_{3}$ complex is not perfectly trigonal but corresponds to a slightly distorted tricapped trigonal prism (see Figure 2). The lowering of symmetry induces a mixing in the GS wavefunction with other $M_{\lrcorner}$states (see Figure 8), which reduces the magnetic moment of the GS. Such an admixture of states cannot be reproduced by a strict trigonal CF. As visible with the calculated ab-initio CF parameters (see Table 1 and Table S5 for the full list), one needs to consider a much lower symmetry, and hence a larger number of CF parameters, in order to get the proper wavefunction. It results in a great reproduction of the magnetic susceptibility and magnetization curves (Figure 3).

Table 1. Experimental and calculated energy splitting (in $\mathrm{cm}^{-1}$ ) of the ground multiplet ${ }^{2} \mathrm{~F}_{7 / 2}$ in $\left[\mathrm{Yb}(R, R)-\mathrm{L}_{3}\right](\mathrm{OTf})_{3}$. The CF parameters $\left(\mathbf{B}_{\mathbf{k}}^{\mathbf{q}}\right.$, in $\left.\mathrm{cm}^{-1}\right)$ deduced from these relative energies and the composition of the GS wavefunction are also given for comparison.

\begin{tabular}{cccc}
\hline & $\begin{array}{c}\text { Lum Sol. } \\
(77 \mathrm{~K})\end{array}$ & $\begin{array}{c}\text { Lum Solid } \\
(77 \mathrm{~K})\end{array}$ & $\begin{array}{c}\text { Ab-initio* } \\
\text { Sol. }\end{array}$ \\
\hline${ }^{2} \mathrm{~F}_{7 / 2}$ & 0 & 0 & 0 \\
& 107 & 109 & 86 \\
& 201 & 194 & 138 \\
& 355 & 348 & 290 \\
$\mathrm{~B}_{2}^{0}$ & -30 & -30 & -24 \\
$\mathrm{~B}_{4}^{0}$ & -98 & -91 & -47 \\
$\mathrm{~B}_{4}^{3}$ & -85 & -173 & -80 \\
$\mathrm{~B}_{6}^{0}$ & -22 & -20 & -11 \\
$\mathrm{~B}_{6}^{3}$ & 1178 & 1183 & -29 \\
$\mathrm{~B}_{6}^{6}$ & 262 & 289 & -56 \\
$\% \mathrm{M}_{\mathrm{J}}= \pm 1 / 2$ & 13 & 14 & 8 \\
$\% \mathrm{M}_{\mathrm{J}}= \pm 3 / 2$ & 0 & 0 & 11 \\
$\% \mathrm{M}_{\mathrm{J}}= \pm 5 / 2$ & 78 & 75 & 63 \\
$\% \mathrm{M}_{\mathrm{J}}= \pm 7 / 2$ & 8 & 11 & 17 \\
\hline${ }^{*}$ the additional ab-initio CF parameters are given in Table S5.
\end{tabular}

At this stage, our objective was to complete the van Vleck puzzle by adding missing pieces, i.e. CF data resulting from $\mathrm{CD}$ and CPL. However, advanced theoretical calculations revealed that chiroptics cannot be treated on the same footing (vide supra). In normal absorption or emission measurements if two different transitions fall at the same wavelength intensities of the transitions gets added: there is no negative absorption or emission. In CD and CPL the signal of each transition at this wavelength can be either positive or negative. The resulting measured signal being the sum it can be positive, negative or even null depending on the respective amplitudes. In other words, the non-observation of a signal does not automatically mean that there are no transitions. It thus makes the analysis of room temperature experiments hazardous especially for lanthanide based complexes in which the crystal field splitting is small and emission lines close to each other's inside the same multiplet, like in $\left[\mathrm{YbL}_{3}\right](\mathrm{OTf})_{3}$ system. Indeed, the $\mathrm{CPL}$ spectrum is temperature dependent with great modulations and shift of the various lines (as demonstrated with calculations; Figure 9). The 
definitive completion of the van Vleck puzzle with chiroptical information will need low temperature CPL and measurements, a task that still needs to be achieved.

\section{Conclusions}

The electronic structure of the chiral $\left[\mathrm{YbL}_{3}\right](\mathrm{OTf})_{3}$ complex has been fully characterized with the help of a combination of magnetic, luminescence and chiroptical characterizations carried out at low and room temperature in solution and in solid-state. We have been able to characterize the energetic splitting of the ground ${ }^{2} F_{7 / 2}$ and excited ${ }^{2} F_{5 / 2}$ terms arising from the crystal-field splitting. The temperature resolved luminescence spectroscopy produced similar electronic structures that with the ab-initio calculations. The CF pictures were then achieved by assuming a perfect trigonal environment ( $D_{3}$ symmetry) that allow to reproduce temperature variation of the magnetic susceptibility. However, these CF pictures were not able to reproduce the proper magnetic moment of ground state because the $\left[\mathrm{YbL}_{3}\right]\left(\mathrm{OTf}_{3} \mathrm{complex}\right.$ exhibits a slight deviation from the ideal $D_{3}$ symmetry. Importantly, quantum calculations shed light on hidden aspects of chiroptical properties: the superposition of various transitions at almost the same wavelength in lanthanide-based complexes truncates the analysis in the Boltzmann landscape. This makes the extraction of CF transitions impossible at room temperature. The quantitative description of chiroptical properties thus waits for low-temperature measurements. In this line, glum values that are considered in the literature as intrinsic observables of each emission line may be experimentally the result of a sum of various contributions and might not be considered definite. In following works, we will combine variable temperatures magneto-lumino-chiroptical techniques on a wider range of symmetries and environments to deeper investigate the CF parameters and complete the van Vleck puzzle.

\section{Acknowledgements}

F.G and B.L.G thank the French GENCI/IDRIS-CINES center for high-performance computing resources. F.G. and B.L.G. acknowledge the Stratégie d'Attractivité Durable (SAD18006—LnCPLSMM). Authors acknowledge support from Agence Nationale de la Recherche (SMMCPL ANR-19-CE29-0012-02) and the European Research Council under the European Union's Horizon 2020 research and innovation program (ERC-CoG MULTIPROSMM, Grant agreement No. 725184).

\section{References}

1 a) J. D. Rinehart and J. R. Long Chem. Sci. 2011, 2, 2078-2085; b) D. N. Woodruff, R. E. P. Winpenny and R. A. Layfield, Chem. Rev., 2013, 113, 5110-5148; c) Z. Zhu, M. Guo, X.-L. Li and J. Tang Coord. Chem. Rev. 2019, 378, 350-364; d) O. Cador, B. Le Guennic and F. Pointillart Inorg. Chem. Front. 2019, 6, 3398-3417; e) M. J. H. Ojea, L. C. H. Maddock and R. A. Layfield, Top. Organomet. Chem. 2019, 64, 253-280; f) L. Escalera-Moreno, J. J. Baldoví, A. Gaita-Ariño and E. Coronado, Inorg. Chem. 2019, 58, 11883-11892.

2 a) C. P. Montgomery, B. S. Murray, E. J. New, R. Pal and D. Parker, Acc. Chem. Res. 2009, 42, 925-937; b) E. G. Moore, A. P. S. Samuel and K. N. Raymond, Acc. Chem. Res. 2009, 42, 542-552; c) E. J. New, D. Parker, D. G Smith and J. W Walton Curr. Opin. Chem. Biol. 2010, 14, 238-246; d) S. V. Eliseeva and J.-C. G. Bünzli Chem. Soc. Rev. 2010, 39, 189-227; e) A. de Bettencourt-Dias, Luminescence of Lanthanide Ions in Coordination Compounds and Nanomaterials, John Wiley \& Sons, Ltd, 2014; e) G.-Q. Jin, Y. Ning, J.-X. Geng, Z.-F. Jiang, Y. Wang and J.-L. Zhang Inorg. Chem. Front., 2020, 7, 289-299; f) N. Hamon, A. Roux, M. Beyler, J.-C. Mulatier, C. Andraud, C. Nguyen, M. 
Maynadier, N. Bettache, A. Duperray, A. Grichine, S. Brasselet, M. Gary-Bobo, O. Maury and R. Tripier J. Am. Chem. Soc. 2020, 142, 10184-10197.

3 a) J. P. Riehl and F. S. Richardson, Chem. Rev. 1986, 86, 1-16; b) G. Muller Dalton Trans. 2009, 9692-9707; c) R. Carr, N. H. Evans and D. Parker Chem. Soc. Rev. 2012, 41, 7673-7686; c) F. Zinna and L. Di Bari Chirality 2015, 27, 1-13.

4 a) S. Shuvaev, E. A. Suturina, K. Mason and D. Parker. Chem. Sci. 2018, 9, 2296-3003; b) M. Leonzio, A. Melchior, G. Faura, M. Tolazzi, M. Bettinelli, F. Zinna, L. Arrico, L. Di Bari and F. Piccinelli New J. Chem. 2018, 42, 7931-7939; c) J. Yuasa, T. Ohno, H. Tsumatori, R. Shiba, H. Kamikubo, M. Kataoka, Y. Hasegawa and T. Kawai Chem. Commun. 2013, 49, 4604-4606; d) K. M. Ayers, N. D. Schley and G. Ung Inorg. Chem. 2020, 59, 7657-7665.

5 M. Górecki, L. Carpita, L. Arrico, F. Zinna and L. Di Bari Dalton Trans. 2018, 47, 7166-7177.

6 F. Zinna, M. Pasini, F. Galeotti, C. Botta, L. Di Bari and U. Giovanella, Adv. Funct. Mater. 2017, 27, 1603719.

7 S. V. Eliseeva and J.-C. G. Bünzli, In Lanthanide spectroscopy, Materials, and Bioapplications; P. Hännen, H. Härmä, Eds.; Springer Series on Fluorescence; Springer Verlag: Berlin, 2010; Vol. 7, Chapter 1.

8 For recent reviews see: a) F. Pointillart, B. le Guennic, O. Cador, O. Maury and L. Ouahab Acc. Chem. Res. 2015, 48, 2834-2842; b) F. Pointillart, O. Cador, B. Le Guennic and L. Ouahab Coord. Chem. Rev. 2017, 346, 150-175; c) J. Long, Y. Guari, R. A. S. Ferreira, L. D. Carlos and J. Larionova Coord. Chem. Rev. 2018, 363, 57-70; d) J.-H. Jia, Q.W. Li, Y.-C. Chen, J.-L. Liu and M.-L. Tong Coord. Chem. Rev. 2019, 378, 365-381; e) R. Marin, G. Brunet and M. Murugesu Angew. Chem. Int. Ed. 2020, doi.org/10.1002/anie.201910299.

9 a) G. Cucinotta, M. Perfetti, J. Luzon, M. Etienne, P.-E. Car, A. Caneschi, G. Calvez, K. Bernot and R. Sessoli Angew. Chem. Int. Ed. 2012, 51, 1606-1610; b) M.-E. Boulon, G. Cucinotta, J. Luzon, C. Degl'Innocenti, M. Perfetti, K. Bernot, G. Calvez, A. Caneschi and R. Sessoli Angew. Chem. Int. Ed. 2013, 52, 350-354.

10 a) Y. Bi, C. Chen, Y.-F. Zhao, Y.-Q. Zhang, S.-D. Jiang, B.-W. Wang, J.-B. Han, J.-L. Sun, Z.-Q. Bian, Z.-M. Wang and S. Gao Chem. Sci. 2016, 7, 5020-5031; b) L. Norel, L. E. Darago, B. Le Guennic, K. Chakarawet, M. I. Gonzalez, J. H. Olshansky, S. Rigaut and J. R. Long Angew. Chem. Int. Ed. 2018, 57, 1933-1938; c) F. Guégan, F. Riobé, O. Maury, J. Jung, B. L. Guennic, C. Morell and D. Luneau Inorg. Chem. Front. 2018, 5, 1346-1353; d) D. Errulat, R. Marin, D. A. Gálico, K. L. M. Harriman, A. Pialat, B. Gabidullin, F. likawa, O. D. D. Couto, J. O. Moilanen, E. Hemmer, F. A. Sigoli and M. Murugesu ACS Cent. Sci. 2019, 5, 1187-1198.

11 a) F. Pointillart, B. Le Guennic, S. Golhen, O. Cador, O. Maury and L. Ouahab Chem. Commun. 2013, 49, 615-617; b) X. Yi, V. Le Corre, G. Calvez, F. Pointillart, O. Cador, B. Le Guennic, O. Maury, V. Placide, Y. Guyot, T. Roisnel, C. Daiguebonne, O. Guillou, A. Caneschi and K. Bernot Chem. Eur. J. 2014, 20, 1569 - 1576; c) K. Soussi, J. Jung, F. Pointillart, B. Le Guennic, B. Lefeuvre, S. Golhen, O. Cador, Y. Guyot, O. Maury and L. Ouahab Inorg. Chem. Front. 2015, 2, 1105-1117; d) K. S. Pedersen, J. Dreiser, H. Weihe, R. Sibille, H. V. Johannesen, M. A. Sørensen,B. E. Nielsen, M. Sigrist, H. Mutka, S. Rols, J. Bendix and S. Piligkos Inorg. Chem. 2015, 54, 7600-7606; e) G. Brunet, R. Marin, M.-J. Monk, U. Resch-Genger, D. A. Gálico, F. A. Sigoli, E. A. Suturina, E. Hemmer and M. Murugesu Chem. Sci. 2019, 10, 6799-6808; f) F. Guégan, J. Jung, B. Le Guennic, C. Mousseigne, F. Riobé, O. Maury, B. Gillon, J.-F. Jacquot, Y. Guyot, C. Morell, and D. Luneau Inorg. Chem. Front. 2019, 6 (11), 3152-3157.

12 D. Guettas, F. Gendron, G. Fernandez Garcia, F. Riobé, T. Roisnel, O. Maury, G. Pilet, O. Cador and B. Le Guennic Chem. Eur. J. 2020, 26, 4389-4395.

13 a) J. P. Leonard, P. Jensen, T. McCabe, J. E. O'Brien, R. D. Peacock, P. E. Kruger and T. Gunnlaugsson J. Am. Chem. Soc. 2007, 129, 10986-10987; b) K.-N. T. Hua, J. Xu, E. E. Quiroz, S. Lopez, A. J. Ingram, V. A. Johnson, A. R. Tisch, A. de Bettencourt-Dias, D. A. Straus and G. Muller Inorg. Chem. 2012, 51, 647-660.

14 J.-H. Van Vleck, J. Phys. Chem. 1937, 41, 67-80. 
15 a) A. Picot, F. Malvolti, B. Le Guennic, P.L. Baldeck, J.A.G. Williams, C. Andraud and O. Maury Inorg. Chem. 2007, 46, 2659-2665; b) A. Picot, C. Feuvrie, C. Barsu, B. Le Guennic, H. Le Bozec, C. Andraud, L. Toupet and O. Maury Tetrahedron 2008, 64, 399-411.

16 a) L. Di Bari, G. Pintacuda, S. Ripoli and P. Salvadori Magn. Reson. Chem. 2002, 40, 396-405; b) J. Lisowski, S. Ripoli and L. Di Bari Inorg. Chem. 2004, 43, 1388-1394.

17 a) M. Lelli and L. Di Bari Dalton Trans. 2019, 48, 882-890; b) L. Di Bari, S. Di Pietro, G. Pescitelli, F. Tur, J. Mansilla and J. M. Saa Chem. Eur. J. 2010, 16, 14190-14201; c) W. Porzio, U. Giovannella, F. Vignali, M. Pasini, S. Destri, A. Mech, S. Di Pietro, L. Di Bari and P. Mineo Inorg. Chem. 2011, 50, 5417-5429; c) S. Di Pietro and L. Di Bari Inorg Chem. 2012, 51, 12007-12014; d) S. Di Pietro, D. Imbert and M. Mazzanti Chem. Commun. 2014, 50, 10323-10326; e) R. Berardozzi, G. Pescitelli, S. Di Pietro, C. Resta, F. P. Ballistreri, A. Pappalardo, G. A. Tomaselli and L. Di Bari Chirality, 2015, 27, 857-863; f) S. Di Pietro, N. Gautier, D. Imbert, J. Pécaut and M. Mazzanti Dalton Trans. 2016, 45, 3429-344.

18 a) L. Bertini and C. Luchinat Coord. Chem. Rev. 1996, 150, 1-300; b) S. Di Pietro, S. Lo Piano and L. Di Bari Coord. Chem. Rev. 2011, 255, 2810-2820.

19 S. De, A. Flambard, D. Garnier, P. Herson, F. H. Köhler, A. Mondal, K. Costuas, B. Gillon, R. Lescouëzec, B. Le Guennic and F. Gendron Chem. Eur. J. 2019, 25, 12120-12136.

20 A. Abragam and B. Bleaney, Electron Paramagnetic Resonance of Transition lons, Clarendon Press. Oxford, 1970. 21 X. Zou and H. Toratani Phys. Rev. B 1995, 52, 15889-15897.

22 C. Reinhard and H. U. Gudel Inorg. Chem. 2002, 41, 1048-1055.

23 F. Silva, O. L. Malta, C. Reinhard, H. U. Gudel, C. Piguet, J. E. Moser and J. C. G. Bunzli J. Phys. Chem. A. 2002, 106, 1670-1677.

24 A. T. Bui, M. Beyler, A. Grichine, A. Duperray, J.-C. Mulatier, Y. Guyot, C. Andraud, R. Tripier, S. Brasselet and O. Maury Chem. Commun. 2017, 53, 6005-6008.

25 G. Lapadula, A. Bourdolle, F. Allouche, M. Conley, I. del Rosa, L. Maron, W. W. Lukens, Y. Guyot, C. Andraud, S. Brasselet, C. Copéret, O. Maury and R. A. Andersen Chem. Mater. 2014, 26, 1062.

26 M. Górecki, L. Carpita, L. Arrico, F. Zinna and L. Di Bari Dalton Trans. 2018, 47, 7166-7177.

27 A.T. Frawley, R. Pal and D. Parker Chem. Commun. 2016, 52, 13349.

28 a) L. Guy, M. Mosser, D. Pitrat, J.-C. Mulatier, M. Kukulka, M. Srebo-Hooper, E. Jeanneau, A. Bensalah-Ledoux, B. Baguenard, S. Guy J. Org. Chem. 2019, 84, 10870-10876, ; b) A.T. Frawley, R. Pal and D. Parker Chem. Commun. 2016, 52, 13349-13353 ; f) L. E. MacKenzie, L.-O. Pålsson, D. Parker, A. Beeby and R. Pal Nat Commun 2020, 11, 1676.

29 For selected recent examples see: a) E. Kreidt, L. Arrico, F. Zinna, L. Di Bari, and M. Seitz Chem. Eur. J. 2018, 24, 13556 - 13564; b) J. Yuasa, T. Ohno, K. Miyata, H. Tsumatori, Y. Hasegawa and T. Kawai J. Am. Chem. Soc. 2011, 133, 9892-9902; c) M. Leonzio, A. Melchior, G. Faura, M. Tolazzi, F. Zinna, L. Di Bari and F. Piccinelli Inorg. Chem. 2017, 56, 4413-4421.

30 a) C. L. Maupin, D. Parker, J. G. Williams and J. P. Riehl J. Am. Chem. Soc. 1998, 120, 10563-10564; b) R. S. Dickins, J. A. Howard, C. L. Maupin, J. M. Moloney, D. Parker, J. P. Riehl, G. Siligardi and J. G. Williams Chem. Eur. J., 1999, 5, 1095-1105; C) C. L. Maupin, C. L. Dickins, L. G. Govenlock, C. E. Mathieu, D. Parker, J. A. G. Williams and J. P. Riehl J. Phys. Chem. A 2000, 104, 6709-6717; d) F. Zinna, L. Arrico and L. Di Bari Chem. Commun. 2019, 55, 6607-6609.

31 For selected recent examples see: a) E. Kreidt, L. Arrico, F. Zinna, L. Di Bari, and M. Seitz Chem. Eur. J. 2018, 24, 13556 - 13564; b) J. Yuasa, T. Ohno, K. Miyata, H. Tsumatori, Y. Hasegawa and T. Kawai J. Am. Chem. Soc. 2011, 
133, 9892-9902; c) M. Leonzio, A. Melchior, G. Faura, M. Tolazzi, F. Zinna, L. Di Bari and F. Piccinelli Inorg. Chem. 2017, 56, 4413-4421.

32 a) F. Gendron, D. Paez-Hernandez, F.-P. Notter, B. Pritchard, H. Bolvin and J. Autschbach Chem. Eur. J. 2014, 20, 7994-8011; b) F. Gendron, B. Pritchard, H. Bolvin and J. Autschbach Dalton Trans. 2015, 44, 19886-19900; c) F. Gendron, H. Bolvin and J. Autschbach Top. Organomet. Chem. 2019, 64, 355-390.

33 F. Gendron, B. Moore II, O. Cador, F. Pointillart, J. Autschbach, B. Le Guennic J. Chem. Theory. Comput. 2019, 15, 4140-4155.

34 K. Binnemans, L. Malykhina, V. S. Mironov, W. Haase, K. Driesen, R. Van Deun, L. Fluyt, C. Görller-Walrand and Y. G. Galyametdinov ChemPhysChem, 2001, 2, 680-683.

35 a) M. Autillo, L. Guerin, T. Dumas, M. S. Grigoriev, A. M. Fedoseev, S. Cammelli, P. L. Solari, D. Guillaumont, P. Guilbaud, P. Moisy, H. Bolvin and C. Berthon Chem. Eur. J. 2019, 25, 4435-4451; b) J. Jung, M. A. Islam, V. L. Pecoraro, T. Mallah, C. Berthon and H. Bolvin Chem. Eur. J. 2019, 25, 15112-15122. 